\title{
Cultural knowledge of non-Muslim nurses working in Saudi Arabian obstetric units
}

\author{
EM Sidumo, MA Cur graduate \\ Department of Health Studies, University of South Africa
}

VJ Ehlers,

Professor, Department of Health Studies, University of South Africa

SP Hattingh, Associate Professor, Department of Health Studies, University of South Africa

\section{Key words}

Breastfeeding, culture competent nursing care, food taboes, Ko’hl, Muslim traditions, non-Muslim nurses, the "evil eye”

\begin{abstract}
Curationis 33 (3): 48-55
Culture defines how persons behave towards each other. When nurses and patients belong to different cultures, culture-based misunderstandings could influence the nurse-patient relationships and interactions adversely. The purpose of the study was to determine non-Muslim nurses' knowledge about Muslim traditions pertaining to obstetric units in a Muslim country. A quantitative descriptive research design was adopted. The population comprised 67 nurses, but the accessible population consisted of 52 nurses who were working in the participating hospital's gynaecological wards during the data collection phase. However, only 50 nurses completed questionnaires as two nurses did not want to participate in the study. The Statistical Package for the Social Sciences (SPSS Version 11.5) was used to analyse the data. The research results indicate that non-Muslim nurses lacked knowledge about Muslim practices concerning breastfeeding, Ko'hl, the "evil eye”, modesty, medicine and food taboos. If these aspects could be addressed during the recruitment and inservice education of non-Muslim nurses working in Muslim countries, this could enhance the quality of culture-competent nursing care.
\end{abstract}

\section{Correspondence address}

Prof VJ Ehlers

ehlervj@unisa.ac.za 


\section{Introduction}

Registered nurses should acknowledge the uniqueness of the cultures they serve and identify cultural barriers impacting on health care services (Roberts, 2002:222). According to Tjale and De Villiers (2004:31), culture comprises a "system of shared ideas, concepts, rules and meanings that shapes people's way of life." Culture also stipulates guidelines to the members of a society as to how they should experience and view the world and how to behave in relation to other people. According to Helman (2002:3) individual, educational, socioeconomic and environmental factors influence the culture, health beliefs and behaviours of individuals.

Cultural knowledge may lead the nurse towards providing cultural competent health care to the patient. Cultural competence as defined by Andrews and Boyle (2003:15) is a "...complex integration of knowledge, attitude and skills..." This process may lead to developing and sharpening one's cultural knowledge and of being able to work effectively within the cultural context of an individual, family or community with diverse cultural backgrounds. The development of cultural competence requires cultural learning, understanding cultural concepts and their effect on the individual's way of life (Tjale \& De Villiers, 2004:32-38). In addition Callister (2001:209) states that cultural competence “...involves moving beyond the biophysical to a more holistic approach and seeking to increase cultural knowledge, change attitudes and hone clinical skills". In a holistic approach, illness and healing can only be addressed in the cultural and religious context within which they occur. As stated by Tjale and De Villiers (2004:4), the traditional health care system is "more holistic in nature" because religion and culture are significant in the healing process. The focus of the traditional health care system is on individuals and meeting their physical and spiritual needs. In contrast to traditional health care, the Western or scientific health care system depends on documented, researched, shared scientific knowledge based on rationality.

Saudi Arabian patients follow tradi- tional health care practices because of their cultural and religious way of life (Leininger \& McFarland, 2002:307). One of the Saudi Arabian cultural practices is the practice of consanguinity, defined as the custom of marrying one's cousin (Panter-Brick, 1991:1295). The Saudi Arabian belief that, "... if you have beauty, intelligence and money why marry outside of the family..." They believe that such marriages strengthen family ties. If an infant born from such a marriage is healthy at birth, then suddenly becomes ill, this illness is attributed to the "evil eye". Within the Saudi Arabian culture, it is believed that, a wicked, jealous or envious female who wants to harm the baby usually casts the "evil eye". In Western societies, consanguinity is viewed as the cause of the high incidence of genetic disorders among Saudi Arabian babies (Panter-Brick, 1991:1297-1299).

\section{Statement of the research problem}

Childbearing women in Saudi Arabia belong to the Muslim faith, requiring strict adherence to cultural expectations during pregnancy and childbirth as well as during the postpartum period and while breastfeeding. Many foreign non-Muslim nurses work in the obstetric units in Saudi Arabia who might not be knowledgeable about these Mulim practices, according to the first author's perceptions while she worked in these units. The question was posed as to whether these foreign non-Muslim nurses possessed sufficient cultural knowledge to provide culturally competent care to the childbearing women in the obstetric units of the participating hospital in Saudi Arabia.

\section{Significance of the study}

Cultural beliefs and values associated with childbearing touches all aspects of persons' social lives (Callister 1995:327). Nursing interventions during pregnancy and childbearing should be culturally sensitive to promote positive outcomes. Nurses thus need culture specific knowledge and skills to care for women and newborns from culturally diverse backgrounds. Cultural competence requires knowledge, awareness and sensitivity to and understanding of the dimensions of the culture served (Tjale \& De Villiers 2004:32).

\section{Purpose of the study}

The study assessed the Saudi Arabian cultural knowledge of the non-Muslim nurses working in the obstetric units of one participating hospital in Saudi Arabia.

The research objectives in this study were to:

- $\quad$ assess non-Muslim nurses’ knowledge about cultural practices associated with pregnancy, labour, postpartum and breastfeeding of the Saudi Arabian childbearing women

- $\quad$ investigate the non-Muslim nurses' knowledge about the cultural taboos, rituals, and health beliefs as practiced by Saudi Arabian women.

\section{Definitions of key concepts \\ Childbearing}

"Child bearing is the process, (in a woman's lifespan), of being pregnant and of giving birth to children" (Longman's Dictionary of Contemporary English, 2005:256). The term is further explained by Andrews and Boyle (2003:96) as " a time of transition and social celebration, it signals a realignment of existing cultural roles and responsibilities, psychological and biological state and social relationships". Childbirth thus depends on the cultural consensus about health, medical care and the status of women.

In this study, childbearing refers to Muslim women's pregnancies and deliveries at the participating hospital.

\section{Culture}

Culture is defined by Hahn (1995:66) as "... a coherent set of values, concepts, beliefs and rules that guide and rationalise people's behaviour in society". On the other hand Helman (2002:2) defines culture as “... that complex whole which includes knowledge, beliefs, art, morals, law, customs and habits acquired by man as a member of society". In addition, Andrews and Boyle (2003:33) explain culture as "...an integrated pattern of human behaviour that includes thoughts, communication, actions, customs, beliefs, 
values, racial, religious or social issues.”

For the purpose of this study, culture is defined as the practices and beliefs that influence the childbearing Saudi Arabian Muslim women's behaviours.

\section{Cultural competence}

Cultural competence is a "...complex integration process of knowledge, attitudes and skills that enhance crosscultural communication, appropriate and effective interaction with others" (Andrews \& Boyle, 2003:15).

In this study, cultural competence refers to the non-Muslim nurse's ability to respect and be sensitive to Saudi Arabian cultural practices, incorporating them in the planned nursing care for childbearing Muslim women.

\section{Cultural practices and health care practices}

Cultural practice may be defined as “...a way that people often do certain actions regularly in order to live their lives according to religious or set rules" (Longman's Dictionary of Contemporary English, 2005:1283).

"Health is a state of being free from illness" "... a person's mental or physical well-being” (The Oxford Handy Dictionary, 2004:414) and care, as “...the process of doing things to keep the body in good condition and working correctly" (Longman English Dictionary, 2005:223).

In this study, cultural practices are those actions to which the childbearing Muslim women have been socialised and are shaped by the Islamic religion. Health care practices refer to Muslim women's actions to achieve physical wellbeing. Muslim childbearing women's cultural practice may influence their health care practices.

\section{Muslim \\ The term Islam means "submission to the will of Allah (God)". "...One who is a follower of the Islamic faith is called a Muslim” (Tjale \& De Villiers, 2004:95).}

In this study, the childbearing women referred to are from Saudi Arabia.

\section{Saudi Arabian}

The Saudi-Arabian according to An- drews and Boyle (2003:477) is a person who resides in Saudi Arabia and who belongs to the Islamic faith. Saudi Arabia is a Middle Eastern country geographically located in the Gulf region of the Asian continent.

\section{Research and methodology}

A quantitative, descriptive, exploratory study design was adopted. The study was quantitative because the SPSS program was used to systematise the information and to calculate statistics. As no research report could be traced about these registered non-Muslim nurses' knowledge about Muslim practices, this study endeavoured to explore and describe such knowledge.

\section{Population}

The population comprised all 62 nonMuslim nurses working at the participating hospital who were rendering care to Saudi Arabian women in the hospital's obstetric units.

Although the population comprised 62 nurses, not all these nurses could be contacted as some were on leave. The accessible population comprised 52 non-Muslim registered nurses working in the obstetric units of the participating hospital during the data collection phase. Only $50(n=50)$ completed questionnaires as two nurses did not want to participate in the study.

\section{Research instrument}

The questionnaire's 33 items attempted to assess the cultural knowledge of the non-Muslim obstetric nurses regarding the taboos, rituals, health care and cultural practices and beliefs of the Saudi Arabian Muslim childbearing women, during pregnancy, the intra-partum period, during anaesthesia and in the postpartum period. Section A of the questionnaire (8 items) requested demographic information from the registered nurses. Section B, comprising 25 questions, assessed the registered nurses knowledge about Muslim childbearing practices. Four Muslim nursing colleagues were asked to validate whether each question would assess non-Muslim nurses’ cultural knowledge.

\section{Pre-testing of the questionnaire}

Four registered nurses completed ques- tionnaires as a trial run to determine if the items were understood and how long it would take to complete the questionnaire. These colleagues were excluded form participating in the actual study. They needed no more than 30 minutes to complete the questionnaires and understood all questions.

\section{Data collection procedure}

The first author distributed the questionnaires to the registered non-Muslim nurses at the beginning of their shifts and requested them to return the completed questionnaires to this researcher. Each respondent completed the questionnaire in her own time and returned the completed questionnaire to the researcher at the end of the shift or whenever she had managed to complete it.

\section{Data analysis}

Data were analysed by using the Statistical Package for the Social Sciences (SPSS Version 11.5) programme with the assistance of a statistician. The data were analysed quantitatively and presented as descriptive statistics in frequency distributions, mostly in the format of tables and graphs.

\section{Ethical considerations}

Approval to conduct the study was granted by the participating hospital's institutional review board and by the Research and Ethics Committee of the Department of Health Studies, University of South Africa.

The respondents had the necessary information and could decide independently whether or not to participate. No written consent was required, in order to ensure anonymity. Only the group's scores were analysed and shared with the nurses working in the obstetric units and the managers during the dissemination of the findings, no reference was made to any individual questionnaire. No compensation was offered.

\section{Research results}

Out of the 50 respondents ( $n=50$ ), 46\% $(n=23)$ fell within the age range of 3140 years followed by $34 \%(n=17)$ aged 41-50; $10 \%(n=5)$ aged $21-30$ and 10\% being 51 or older. Out of the 50 respondents, 94\% ( $n=47)$ were Christians whereas only $2 \%(n=1)$ belonged to the 
to "other" unspecified religions.

The majority of the respondents (74\%; $n=37$ ) were Filipinos followed by $20 \%(n=10)$ South Africans; Indians and Europeans comprised $4 \%(n=2)$ and $2 \%(n=1)$ respectively. Out of the 50 respondents, $88 \%$ $(n=44)$ had more than five years' nursing experience; $44 \%(n=22)$ worked in the obstetric and gynaecology inpatient unit, followed by $28 \%(n=14)$ who worked in the labour and delivery unit. The artificial reproductive technology and obstetric and gynaecology outpatient units had $16 \%(n=8)$ and $12 \%$ $(n=6)$ respectively.

Only $22 \%(n=11)$ of the respondents had less than one year's experience in their current units and $50 \%(n=25)$ had been in Saudi Arabia for seven years and longer

\section{Cultural and health care practices of Muslim women}

Some respondents did not complete every question, accounting for the differences in the total number of responses to different items.

\section{Herbal remedies used during pregnancy}

Although $48 \%(n=24)$ of the registered nurses indicated that they never asked the pregnant women whether they used herbal remedies or not, 38\% $(n=19)$ occasionally asked and only $14 \%(n=7)$ always asked mothers this question on admission. When asked to list the herbs used by Muslim women, the majority (86\%; n=43) said they did not know such herbs' names. Each respondent could supply more than one answer. However, some non-herbal remedies were mentioned. Dates, juice, sand, carwa, splina and tarya oil cannot be classified as herbs (Free Online Dictionary, 2008). The correct responses included castor oil (8), mint/mint leaves (4), cardamom (2) and lemon (1).

\section{Printer to place figure.}

According to Burns (2001:1), mint is being used by Saudi Arabians in their tea for flavour and in the treatment of fever, while lemon balm is used as a headache remedy or for aiding circulation or as an anti-septic agent. Castor oil and cardamom are herbs used as laxatives and antispasmodic agents respectively (Free Online Dictionary, 2008).

\section{Nurses' knowledge about diseases common among Saudi Arabians}

This knowledge was deemed essential as some genetic conditions are prevalent among Muslims, especially those who marry their cousins. Nurses should be able to provide relevant genetic counselling or refer the patients to genetic counsellors. According to $34 \%(n=17)$ of the respondents, they always considered common diseases. However, 42\% ( $n=21)$ occasionally did so and $18 \%(n=9)$ never did this.

The practice of consanguinity among the Saudi Arabian population contributes to the high rate of congenital metabolic and neurological conditions among this cultural group. Thalassaemia, sickle cell anaemia, hepatitis B and systemic lupus erythematosis are some of the common diseases among Saudi Arabians (Al-Aqeel 2004; Panter-Brick 1991:1297).

Responses of thalassaemia $(n=4)$, sickle cell anaemia $(n=2)$, systemic lupus erythematosis (1), hepatitis B ( $n=4)$ and congenital heart disease $(n=2)$ indicate that only a few respondents could identify conditions commonly found among Saudi Arabians. Conditions such as hypertension, depression, and pregnancy-induced hypertension were listed by the respondents but these conditions are not specific to Saudi Arabians.

Of the respondents $60 \%(n=30)$ always included cultural aspects in their nursing care plans, whereas $18 \%(n=9)$ occasionally did so and $16 \%(n=8)$ never did this. According to Wells (2000:199) nurses are encouraged to develop care plans that incorporate cultural aspects in the management of a patient's condition.

\section{Muslim cultural practices associated with the placenta, umbilical cord and umbilical stump}

Muslim rules specify that the placenta 
should be handed to the family to send home for burial. According to Roberts (2003:252), Muslim families prefer to dispose of the placenta by burial, as this is believed to be a symbolic return of the placenta to its creator (Allah).

Of the respondents, 54\% ( $n=27)$ indicated that they did not know what happens to the placenta, while $22 \%(n=11)$ stated that Muslims would take the placenta home for burial. Of the respondents, 56\% $(n=28)$ reported that they did not know how Saudi Arabian women traditionally cared for the umbilical cord, $10 \%(n=5)$ mentioned that the mother applied a binder to the umbilical cord, $2 \%(n=1)$ reported they applied “ko'hl” and 4\% (n=2) mentioned that Muslims buried the stump of the umbilical cord where the placenta was buried. According to Leininger and McFarland (2002:102), Muslims apply "ko'hl” to the umbilical cord to facilitate drying.

\section{Considerations of geographic, cultural, religious affiliations and occupations of the patients during assessment}

Upon admission or first encounter of the nurse with the patient certain subjective data should be gathered in order to develop a plan of care based on the information obtained.

Figure 1 illustrates the nurses' considerations of geographic and cultural aspects, religious affiliations and the patients' occupations during the initial assessments of the patients.

From the information depicted in Figure 1 , half of the respondents (50\%; $\mathrm{n}=25$ ) always considered the geographic origins of the patients; $32 \%$ $(n=16)$ occasionally considered the geographical origins and 14\% $(n=7)$ never did so. Of the respondents, 70\% (n-35) always asked the patients about their cultural origins, $20 \%(n=10)$ occasionally did this while $8 \%(n=4)$ never did so. When interacting with the patient, $70 \%(n=35)$ always asked the patients about their religious affiliations, whereas $14 \%(n=7)$ sometimes asked and $14 \%(n=7)$ never asked this question.

Only 56\% $(n=28)$ respondents reported that they always asked about the pa-

Table 1: Practices associated with the prevention of ill health to the baby $(\mathrm{n}=48)$

\begin{tabular}{|l|l|}
\hline Response & Frequency \\
\hline Don't know & 52 \\
\hline Saying bismillah & 1 \\
\hline Giving dates to the newborn & 8 \\
\hline Importance of baby check up & 1 \\
\hline To say a prayer right after the delivery & 5 \\
\hline Giving honey & 1 \\
\hline Leaving the Qur'an with the baby in the cot & 2 \\
\hline Always saying hamdulillah & 1 \\
\hline Black necklace with an eye pendant to prevent the evil eye & 1 \\
\hline Reading verses from the Qur'an & 1 \\
\hline Use of Ko'hl around the baby's eyes & 8 \\
\hline Importance of vaccination & 1 \\
\hline Non applicable & 2 \\
\hline Washing in holy water at birth & 1 \\
\hline If you want to give a complement “your baby is beautiful” & 6 \\
\hline Breastfeeding & 1 \\
\hline Religious rituals done immediately post delivery & 1 \\
\hline The use of amulets & 1 \\
\hline Needed sunlight & 1 \\
\hline Now a days they do not care & 1 \\
\hline Total & 1 \\
\hline
\end{tabular}

tients' occupations, 36\% (n=18) occasionally did so and $6 \%(n=3)$ never asked this question.

\section{Saudi Arabian cultural practices associated with prevention of the baby's ill health}

Zahr and Hattar-Pollara (1998:354) mention that amulets such as beads and verses of the Qur'an are used by Muslims to protect babies from the harmful effects of the "evil eye" that causes ill health. The father may read the Qur' an to the baby to ward off the "evil eye" (Panter-Brick 1991:1297). Whispering in a baby's ear by the father (Roberts, 2003:254), the use of amulets, or blue beads, include attempts to ward off the “evil eye” (Zahr \& Pollara, 1998:354).

\section{Cultural beliefs of Muslim women regarding breastfeeding}

Of the 50 respondents, $28 \%(n=14)$ reported that they did not know what the 
attitudes of Muslim women were regarding breastfeeding. Thirty eight percent $(n=19)$ of the respondents commented that the Muslim mother is "reluctant”, "lazy”, “not keen”, "not eager to" and reports "not enough milk" and that the "milk will not come" in order to avoid breastfeeding. In contrast to this, 14 (28\%) respondents indicated that the Muslim mothers knew the importance of bonding and they were proud to be mothers, who preferred to breastfeed. According to AlJassir, El-Bashir, Moizuddin and AbuNayan (2006:8), Saudi Arabian mothers often bottle-feed their babies because they assume that their breasts have no milk or that the milk is of a poor quality. Roberts (2003:253) emphasises that modesty and privacy concerns might prevent the Muslim mother from breastfeeding in the presence of other people.

\section{Rituals performed by the Muslim father after birth}

Of the respondents, $22 \%(n=11)$ reported that they did not know what rituals are performed by the father to the newborn baby. However, 34\% ( $n=17)$ stated that the father would whisper a prayer to the baby's ears and $4 \%(n=2)$ mentioned that the father would recite the Qur'an. Another 34\% (n=17) mentioned that the father or grandfather or priest would pray for the newborn baby. Two percent $(n=1)$ mentioned that the father would dance with the baby. According to Leininger and McFarland (2002:484) the father whispers a prayer to the baby's ears and Panter-Brick (1991:1297) mentions that the father may read the Qur'an to or cleanse the baby with water containing the seeds of dates immediately after birth.

\section{Muslims' taboos regarding medications and food}

From the 50 respondents, 56\% $(n=28)$ reported that they did not know what taboos are associated with medication use among Muslims. Ten percent $(n=5)$ of the respondents mentioned that it is a taboo to give medication to the Muslim using the left hand and $8 \%(n=4)$ reported that medication containing alcohol and prohibited drugs are also regarded as taboos. Four percent $(n=2)$ of the respondents mentioned that it is a taboo to give intravenous medication during the month of Ramadan. Four

Table 2 Challenges encountered when caring for Saudi Arabian patients $(n=50)$

\begin{tabular}{|c|c|c|}
\hline Response & Frequency & Percent \\
\hline Don’t know & 8 & 16.0 \\
\hline Nothing or no experience & 9 & 18.0 \\
\hline $\begin{array}{l}\text { The relatives and family interfere in } \\
\text { the care of the patient }\end{array}$ & 8 & 16.0 \\
\hline Language barriers & 7 & 14.0 \\
\hline $\begin{array}{l}\text { Privacy issues: uncooperative during } \\
\text { examinations and refusal to be exam- } \\
\text { ined by men }\end{array}$ & 5 & 10.0 \\
\hline $\begin{array}{l}\text { Attitudes towards the nurses: Sau- } \\
\text { dis are demanding }\end{array}$ & 4 & 8.0 \\
\hline $\begin{array}{l}\text { Cultural issues: During Ramadan } \\
\text { most women are fasting even when } \\
\text { pregnant and/or sick and refuse treat- } \\
\text { ment }\end{array}$ & 3 & 6.0 \\
\hline $\begin{array}{l}\text { Attitude towards health: Lack of } \\
\text { knowledge regarding health issues }\end{array}$ & 2 & 4.0 \\
\hline $\begin{array}{l}\text { Visitors: The large number of visitors } \\
\text { per patient is frustrating. }\end{array}$ & 3 & 6.0 \\
\hline $\begin{array}{l}\text { Limited knowledge about their culture } \\
\text { and practices }\end{array}$ & 1 & 2.0 \\
\hline Total & 50 & 100.0 \\
\hline
\end{tabular}

percent $(n=2)$ of the respondents who indicated that the food should be "halal" however they did not explain what "halal" means neither why food should be "halal" . In addition, 36\% $(n=18)$ of the respondents remarked that no pork is allowed and $4 \%(n=2)$ reported that there are restrictions of food associated with the month of Ramadan.

Roberts (2003:253), as well as Leininger and McFarland (2002:307), mention that medications with hidden ingredients like alcohol (often contained in cough mixtures) or pork (for example Insulin) are taboos for the Muslims.

\section{Saudi Arabian cultural} concepts: "henna", "evil eye", consanguinity, "ko'hl" and modesty principles
"Henna"

Of the respondents, 20\% ( $\mathrm{n}=10)$ did not know what "henna" is; $12 \%(n=6)$ mentioned that "henna" is used for cosmetic and beautification purposes; 22\% $(\mathrm{n}=11)$ indicated Muslim women use henna to paint or dye the hair; $10 \%$ $(n=5)$ that it is used for art; $12 \%(n=6)$ that brides use "henna" at weddings and $16 \%(n=8)$ reported henna was used to paint the nails and hands. Henna is a herbal substance applied on the hands and soles of the feet as a good omen in marriages and has a cooling effect during the hot summer months (Leininger \& McFarland, 2002:102).

\section{"Evil eye"}

Of the respondents, 42\% ( $n=21)$ indicated they did not know the meaning of the concept "evil eye", 6\% $(n=3)$ mentioned that the application of 
"ko' $h l$ " over the eye is an attempt to prevent the effects of the "evil eye" but $22 \%(n=11)$ of the responses were non-specific such as "...looking through the eye", "bad luck" and "the baby is gorgeous".

When praise is given to a Muslim it should be followed by the word "masha Allah" which means, "thanks to God for the blessings", according to $24 \%(n=12)$ of the respondents. According to Lovering (2006:392) Muslims believe that if a baby or a person is praised, the praise should be concluded by "masha Allah" otherwise the person who is praised will become ill; Allah should be acknowledged because He is the provider of protection against the "evil eye".

\section{Consanguinity}

Only $4 \%(n=2)$ of the respondents indicated that consanguinity is a cultural belief among Muslims of allowing marriages between cousins. Four percent $(n=2)$ mentioned marriage between families, and $20 \%(n=10)$ listed marriage between relatives as a general practice. The majority $62 \%(n=31)$ of the respondents did not know what the concept consanguinity meant. Panter-Brick (1991:1299) defines consanguinity as the "custom of marrying cousins" which is practised among Saudi Arabians.

\section{"Ko'hl"}

Of the respondents, 58\% ( $\mathrm{n}=29)$ did not know what " $k o$ ' $h l$ " is, $2 \%(\mathrm{n}=1)$ listed "cough", 20\% $(\mathrm{n}=10)$ indicated that " $k o$ ' $h l$ " is used on the eyebrows for cosmetic and for beauty purposes and $10 \%(n=5)$ mentioned that it is used to protect the baby by warding off the "evil eye". According to Leininger and McFarland (2002:102) “ko'hl” is a charcoal like substance used as eye cosmetics and it might be applied to the umbilical cord to facilitate drying.

\section{Modesty}

As many as $48 \%(n=24)$ of the respondents indicated that they did not know what modesty meant within the Saudi Arabian cultural context. However, $10 \%(n=5)$ mentioned that modesty refers to the way persons greet each other and one (2\%) mentioned that women are not allowed to smoke. Although all women wear 'abayas' in Saudi Arabia, only $16 \%(n=8)$ of the respondents mentioned that modesty implies that Muslim women should be covered by wearing the "tarha" and “abaya” while 14\% (n=7) mentioned that modesty implied that men should not come into contact with women. These responses are supported by AlShahri (2002:135) and Galanti (2006:98) who maintain that it is important for Saudi Arabian women to cover their bodies and to be separated from men in public.

\section{Nurses' knowledge regarding Saudi Arabian language, culture, health care beliefs and practices}

Respondents were asked to assess themselves using the rating scale of 1 indicating poor and 10 indicating excellent knowledge. Of the 50 respondents, $6 \%(n=3)$ did not answer this question, $60 \%(n=30)$ rated themselves between 1 and 5 whereas 34\% ( $n=17)$ rated themselves between 6 and 10 . This is an indication that more than half of the respondents indicated that they had limited knowledge about the Saudi Arabian culture, health care beliefs and practices. Asked whether they wanted to learn more about the Saudi Arabian cultural practices, $90 \%(n=45)$ replied in the affirmative, $8 \%(n=4)$ were not interested and 2\% ( $n=1)$ did not respond to this question. Of the respondents 34\% ( $n=17)$ rated their understanding of Saudi Arabian cultural and health care beliefs between 1 and 5 while 44\% $(n=22)$ rated their understanding of the Saudi Arabian taboos and rituals between 1 and 5. Of the 50 respondents, $2 \%(n=1)$ did not answer the question about their ability to speak Arabic, 76\% $(n=38)$ rated themselves from 1 to 5 , and $22 \%(n=11)$ between 6 to 10 .

\section{Saudi Arabian cultural challenges encountered by nurses}

Challenges mentioned by $70 \%(n=35)$ of the respondents included communication barriers, privacy issues, religious obligations, cultural issues, visitors and family involvement in the management of the patient. According to Leininger and McFarland (2002:308) the family, especially the male figure head, is the decision maker and the presence of a large number of family members and visitors demonstrates a caring attitude towards the patient.

\section{Cultural awareness presentations by the recruitment agency}

Out of the participating non-Muslim registered nurses, $74 \%(n=37)$ indicated that they had received cultural awareness lectures from their recruitment agents before leaving their countries for Saudi Arabia. The other $24(n=12)$ did not receive such information and $2 \%(n=1)$ did not respond to the question. Cultural awareness lectures, according to $80 \%(n=40)$ of the respondents, were offered by the participating hospital, and $86 \%(n=43)$ of the nonMuslim registered nurses desired to participate in educational activities regarding Saudi Arabian culture, especially topics related to antenatal care, labour and breastfeeding practices.

\section{Conclusion}

The 50 non-Muslim expatriate registered nurses who worked in Saudi Arabia, and participated in this study by completing questionnaires, lacked cultural knowledge about

- Saudi Arabian women's use of herbs

- $\quad$ Diseases specific to the Saudi Arabian population

- $\quad$ Cultural practices during antenatal, intra- and post partum periods and breastfeeding

- $\quad$ Practices preventing ill health to the baby, including cultural expectations concerning the father's role and the disposal of the placenta and umbilical cord

- Ko' Ko', the “evil eye”, modesty, and medicine and food taboos

According to the respondents' selfevaluations, 60\% $(n=30)$ lacked Saudi Arabian cultural knowledge, while 86\% $(n=43)$ were interested in educational activities about the Saudi Arabian culture.

\section{Limitation of the study}

The research results should be interpreted against the following limitations of this study:

- $\quad$ Generalisation of the study findings is not possible because the study was conducted only in the obstetric units of one par- 
ticipating hospital .

- $\quad$ Relatively few registered nurses completed questionnaires $(n=50)$.

- Most participants came from the Philippines and from South Africa. Thus the research findings might be not be generalisable to expatriate nurses from other countries working in Saudi Arabia.

- $\quad$ Data collection was done only by self-completion questionnaires. Conducting semi-structured or focus group interviews might have produced more indepth views about the Saudi Arabian cultural challenges posed to expatriate nurses working in obstetric units.

\section{Recommendations}

Culture competent care can be enhanced at the participating hospital by

- $\quad$ Enhancing the hospital's existing educational programmes about Saudi Arabian cultural aspects

- Developing a cultural resource centre, including information brochures, literature reviews on health-related topics of the Saudi Arabians and access to relevant Websites

- $\quad$ Encouraging the inclusion of culture-specific aspects in the nursing care plan for each patient

- $\quad$ Identifying a knowledgeable person as a resource person to be consulted by expatriate nurses

Future research could be conducted on the following topics:

- $\quad$ Evaluations before and after educational interventions on cultural aspects

- $\quad$ Similar studies should be conducted in other units such as the paediatric, orthopaedic, surgical and medical units

- $\quad$ Expatriate nurses' lived experiences of caring for Saudi Arabian childbearing women should be recorded.

\section{References}

AL-AQEEL, MD 2004: Common ge- netic and metabolic diseases in Saudi Arabia. Middle East Journal of Family Medicine, 23(8):909=914.

AL-JASSIR, MS; EL-BASHIR, BM; MOIZUDDIN,SK \&ABU-NAYAN,AA 2006: Infant feeding in Saudi Arabia: mothers' attitudes and practices. East Mediterranean Health Journal, 12 (12):6-13.

AL-SHAHRI, MZ 2002: Culturally sensitive care for Saudi Arabian patients. Journal of Transcultural Nursing, 13(2):133-138.

ANDREWS, MM \& BOYLE, JS 2003: Transcultural concepts in nursing care. $4^{\text {th }}$ edition. Philadelphia: JB Lippincott.

BURNS, K 2001: Drugs, medicine, herbs and birth defects. [Online] http://www.islaonline.net/english/Science/article2.shtm (accessed 19 November 2007 at 16:00).

CALLISTER, LC 1995: Cultural meaning to childbirth. Journal of Obstetrics, Gynaecologic and Neonatal Nursing, 24(4):327-331.

CALLISTER, LC 2001: Culturally competent care of women and newborns: knowledge, attitudes, and skills. Journal of Obstetrics, Gynaecologic and Neonatal Nursing, 30(2):209-215.

\section{FREE ONLINE DICTIONARY 2008:}

[Online] Available: http:// www.Marriem-Webster.com Accessed 02 January 2008

GALANTI, GA 2006: Applying cultural competence to perianesthesia nursing. Journal of Perianesthesia Nursing, 21(2):97-102.

HAHN, R 1995: Sickness and health: an anthropological perspective. London: Yale University Press.

HELMAN, CG 2002: Culture, health and illness. 4th edition. London: Butterworth/Heinemann.

LEININGER,M \& McFARLAND,MR 2002: Transcultural nursing: concepts, theories, research and practice. $3^{\text {rd }}$ edition. New York: McGraw Hill.

LONGMAN'S DICTIONARY OF CONTEMPORARY ENGLISH. 2005:
The living dictionary. $4^{\text {th }}$ edition. Rome: La Tipografica Varese.

LOVERING, S 2006: Cultural attitudes and beliefs about pain. Journal of Transcultural Nursing, 17(4):389-395.

PANTER-BRICK, C 1991: Parental responses to consanguinity and genetic disease in Saudi Arabia. Social Science \& Medicine. 33(11):1295-1302.

ROBERTS, KS 2002: Providing culturally sensitive care to the childbearing Islamic family. Advances in Neonatal Care, 2(4):222-228.

ROBERTS, KS 2003: Providing culturally sensitive care to the childbearing Islamic family: part II. Advances in Neonatal Care, 3(5):250-255.

THE OXFORD HANDY DICTIONARY 2004: London: Oxford University Press.

TJALE, A \& DE, VILLIERS L (eds) 2004: Cultural issues in health and health care. Cape Town: Juta.

WELLS, MI 2000: Beyond cultural competence: a model for individual and institutional cultural development. Journal of Community Health Nursing, 17(4):189-99.

ZAHR,LK\& HATTAR-POLLARA,M 1998: Nursing care of Arab children: consideration of cultural factors. Journal of Paediatric Nursing,13(6):349-355. 